\title{
Circulating MiR-1290 as a potential diagnostic and disease monitoring biomarker of human gastrointestinal tumors
}

Liyi Xu' ${ }^{1}$ Yangke Cai ${ }^{1}$, Xiao Chen ${ }^{2}$, Yongliang Zhu ${ }^{1 *}$ and Jianting Cai ${ }^{1 *}$

\begin{abstract}
Background: Gastrointestinal tumors are a leading cause of mortality worldwide. As shown in our previous study, miR-1290 is overexpressed in colorectal cancer (CRC) and promotes tumor progression. We therefore aimed to explore the potential of circulating miR-1290 as a biomarker for gastrointestinal cancer.

Methods: A serum miRNA sequencing analysis was performed. Then, circulating miRNA detection technologies were established. The expression of miR-1290 was analyzed in gastrointestinal tumor cell lines and culture supernatants. Expression levels of circulating miR-1290 in clinical samples were examined. Associations between miR-1290 expression and clinicopathologic characteristics were analyzed. Xenograft models were generated to assess the fluctuation in serum miR-1290 levels during disease progression.

Results: Through miRNA sequencing, we identified that miR-1290 was overexpressed in serum samples from patients with CRC. We confirmed that human gastrointestinal tumor cells express and secrete miR-1290. The circulating miR-1290 levels was up-regulated in patients with pancreatic cancer (PC) $(p<0.01), C R C(p<0.05)$, and gastric cancer (GC) $(p<0.01)$. High miR-1290 expression levels were associated with tumor size, lymphatic invasion, vascular invasion, distant metastasis, tumor differentiation and AJCC stage in patients with PC and CRC. The area under the curve (AUC) was 0.8857 in patients with PC, with $60.9 \%$ sensitivity and $90.0 \%$ specificity. The AUC was 0.7852 in patients with CRC, with $42.0 \%$ sensitivity and $90.0 \%$ specificity. In patients with GC, the AUC was 0.6576 , with $26.0 \%$ sensitivity and $90.0 \%$ specificity. The in vivo model verified that the circulating miR-1290 level was significantly increased after tumor formation and decreased after drug treatment.
\end{abstract}

Conclusions: Our findings indicate that circulating miR-1290 is a potential biomarker for gastrointestinal cancer diagnosis and monitoring.

Keywords: Gastrointestinal tumor, Circulating miRNA, miR-1290, Diagnosis, Surveillance, Biomarker

\footnotetext{
* Correspondence: ylzhu@zju.edu.cn; jtcai6757@zju.edu.cn

'Department of Gastroenterology, The Second Affiliated Hospital, School of Medicine, Zhejiang University, Hangzhou 310009, Zhejiang, Province, China

Full list of author information is available at the end of the article
}

(c) The Author(s). 2021 Open Access This article is licensed under a Creative Commons Attribution 4.0 International License, which permits use, sharing, adaptation, distribution and reproduction in any medium or format, as long as you give appropriate credit to the original author(s) and the source, provide a link to the Creative Commons licence, and indicate if changes were made. The images or other third party material in this article are included in the article's Creative Commons licence, unless indicated otherwise in a credit line to the material. If material is not included in the article's Creative Commons licence and your intended use is not permitted by statutory regulation or exceeds the permitted use, you will need to obtain permission directly from the copyright holder. To view a copy of this licence, visit http://creativecommons.org/licenses/by/4.0/ The Creative Commons Public Domain Dedication waiver (http://creativecommons.org/publicdomain/zero/1.0/) applies to the data made available in this article, unless otherwise stated in a credit line to the data. 


\section{Background}

Gastrointestinal tumors are the most common cancers worldwide $[1,2]$. Colorectal cancer (CRC) and pancreatic cancer (PC) have the highest incidence and mortality rates among gastrointestinal tumors in the United States [1]. Compared to Western countries, China has a similar incidence of CRC but a significantly higher incidence of liver cancer and gastric cancer (GC). In 2018, gastrointestinal (stomach, liver, and esophagus) cancerrelated deaths accounted for $36.4 \%$ of tumor-related deaths in China, while digestive cancer-related deaths comprised less than $5 \%$ of total cancer-related deaths in Western countries [3]. This difference may be related to the low early detection rate in China and the lack of uniformity of clinical treatment strategies in different regions. Therefore, population-based tumor screening can significantly increase the tumor detection rate, reduce tumor-related mortality, and improve patient prognosis. An effective screening method with high population coverage and compliance could have great clinical significance.

MicroRNAs (miRNAs) are non-coding, singlestranded, small RNAs of approximately 19-23 nucleotides, which widely exist in various organisms. Notably, miRNAs directly affect the cellular stability of messenger RNA (mRNA), thereby regulating gene expression at the posttranscriptional level and forming complex regulatory networks in cell proliferation, differentiation, apoptosis, homeostasis and stress response [4]. Extracellular/circulating miRNAs exist in various biological fluids, such as serum, plasma, saliva, urine, cerebrospinal fluid, and breast milk. They are delivered to target cells and act as autocrine, paracrine, and/or endocrine modifiers of cell activity [5]. Circulating miRNAs are potential diagnostic and prognostic biomarkers for various diseases [6].

An appropriate detection method is an essential step for liquid biopsy based on cell-free miRNA. The extraction efficiency, stability of internal controls and methodological accuracy all must be considered before clinical application [7]. Although numerous studies have been conducted to screen and identify circulating miRNAs as efficient biomarkers for specific types of tumors, the diagnostic value of a certain biomarker in different tumors must be evaluated, considering the broad spectrum of tumor markers.

As shown in our previous study, miR-1290 is overexpressed in clinical tumor tissues from patients with colon cancer and promotes tumor progression. However, we have not clearly determined whether miR-1290 can serve as a marker for early diagnosis and disease monitoring. In this study, miR-1290 expression in the serum from patients with gastrointestinal tumors was analyzed through miRNA sequencing, and a circulating miRNA detection method was built and evaluated. The diagnostic value of miR-1290 was verified for different tumors (including PC, CRC, and GC), and clinical characteristics of patients were collected to study the correlation between miR-1290 expression and clinicopathologic features. Meanwhile, a xenograft tumor model was established to explore the role of serum miR-1290 in disease surveillance. Therefore, we aimed to explore the potential of circulating miR-1290 to serve as a biomarker for gastrointestinal cancer.

\section{Methods}

\section{Patients and clinical specimens}

In this study, blood samples from 46 patients with PC, 50 patients with $\mathrm{CRC}, 50$ patients with $\mathrm{GC}$, and 50 healthy individuals were obtained at the Second Affiliated Hospital of Zhejiang University School of Medicine, Hangzhou, China, between January 2017 and December, 2019. Tumor tissues and adjacent non-tumor tissues were collected from ten patients with CRC. All patients with gastrointestinal tumors were enrolled at the initial diagnosis of tumors, and pathological diagnoses were subsequently confirmed.

\section{Sample processing}

Blood samples were obtained by venipuncture. Serum samples were collected from whole blood in coagulation tubes, and plasma samples were processed from whole blood collected in an EDTA anticoagulation tubes (BD, New Jersey, USA). Blood samples were stored at $4{ }^{\circ} \mathrm{C}$ and processed within $4 \mathrm{~h}$. Each sample was centrifuged at $1900 \mathrm{~g}(3000 \mathrm{rpm})$ at $4{ }^{\circ} \mathrm{C}$ for $10 \mathrm{~min}$, and the supernatant was placed in a new centrifuge tube and centrifuged again at $16000 \mathrm{~g}$ at $4{ }^{\circ} \mathrm{C}$ for $10 \mathrm{~min}$ to remove the residual nucleic acid attached to the cell debris. Serum/ plasma samples that were able to be examined on the same day were stored at $2-8{ }^{\circ} \mathrm{C}$, and samples requiring long-term storage were stored at $-80^{\circ} \mathrm{C}$.

\section{miRNA sequencing}

Three pairs of serum samples from CRC patients and healthy controls matched for clinical characteristics such as age, sex, and past history, were selected from our study group for miRNA sequencing. Sequencing was performed on Illumina Hiseq2000/2500 system (LC Science, USA) following the manufacturer's protocol. Differentially expressed miRNAs based on normalized deep-sequencing counts were analyzed using Student's t test. The screening criteria were a fold change $>2$ and $p<0.01$. The Venn diagram of miRNAs was generated through the online analysis tool Draw Venn Diagram (http://bioinformatics.psb.ugent.be/webtools/Venn/).

The volcano map, heatmap and cluster analysis were conducted through online analysis tools (https://www. omicstudio.cn/tool). 
Target gene prediction, functional enrichment analysis, interaction network analysis and phylogenetic analysis The target genes of miRNAs were predicted by the TargetScan and miRanda. The Database for Annotation, Visualization and Integrated Discovery (DAVID; https:// david.ncifcrf.gov/) was a web-accessible functional annotation tool for GO and KEGG pathway enrichment analysis. False discovery rate (FDR) $<0.01$ was considered as the threshold value. miRNA-mRNA interaction network analysis was realized by the Cytoscape (version 3.7.1), an open bioinformatics software. The phylogenetic tree was built with MEGA (version 7.0.20).

\section{Cell culture}

The PC cell lines AsPC-1, BxPC-3, and SW1990, the CRC cell lines HT-29, HCT116, RKO, SW620, and SW480, and the GC cell lines SGC7901 and BGC823 were purchased from the Cell Bank of the Shanghai Branch of the Chinese Academy of Sciences. Primary CRC P4 cells were established in our laboratory from primary colorectal cancer tissues. AsPC-1, BxPC-3, SGC7901, and BGC823 cells were cultured in RPMI1640 medium (Corning, New York, USA); SW1990, SW620, and SW480 cells were cultured in Leibovitz's L15 medium (Corning, New York, USA); and HT-29 and HCT116 cells were cultured in McCoy's 5A medium (Corning, New York, USA). RKO cells were cultured in Minimum Essential Medium (MEM) (Corning, New York, USA). All cell culture media were supplemented with penicillin $\mathrm{G}(100 \mathrm{U} / \mathrm{ml})$, streptomycin $(100 \mu \mathrm{g} / \mathrm{ml})$ and $10 \%$ fetal bovine serum (FBS) and grown at $37^{\circ} \mathrm{C}$ with $5 \% \mathrm{CO} 2$.

\section{Internal and exogenous controls}

The internal and exogenous controls were hsa-miR-165p (H. sapiens; 5' -UAGCAGCACGUAAAUAUUGGCG$3^{\prime}$ ) and cel-miR-39 (C. elegans; 5'-UCACCGGGUG UAAAUCAGCUUG-3') (RIBOBIO, Guangzhou, China), respectively. Then, $1 \mathrm{nmol}$ of the cel-miR-39 standard was dissolved in $50 \mu \mathrm{l}$ of nuclease-free water to obtain a $20 \mu \mathrm{M}$ stock solution. The stock solution was diluted to $10 \mathrm{nM}$, and $5 \mu \mathrm{l}$ of the $10 \mathrm{nM}$ cel-miR-39 standard was added to each $200 \mu \mathrm{l}$ volume of sample during circulating miRNA extraction.

\section{Isolation of cell-free miRNA and total RNA}

Cell-free miRNA (including circulating miRNA and cellfree miRNA in the cell supernatant) was isolated from $200 \mu \mathrm{l}$ of serum or plasma using five different commercially available extraction kits or reagents (Table S1) according to the manufacturer's protocol. Total RNA was extracted from tissue samples and cultured cells using TRIzol reagent (Invitrogen, CA, USA).

\section{Reverse transcription}

Total miRNA pools were used as the template for cDNA synthesis with the miRNA First Strand cDNA Synthesis Kit (Sangon Biotech, Shanghai, China) according to the manufacturer's instructions. The following conditions were used: $16^{\circ} \mathrm{C}$ for $30 \mathrm{~min}, 37^{\circ} \mathrm{C}$ for $30 \mathrm{~min}$, and $85^{\circ} \mathrm{C}$ for $5 \mathrm{~min}$. The reverse transcription primer for hsa-miR1290 was 5'- GTCGTATCCAGTGCAGGGTCCGAG GTATTCGCACTGGATACGACTCCCTG-3' (Sangon Biotech, Shanghai, China), the reverse transcription primer for hsa-miR-16-5p was 5'- GTCGTATCCAGT GCAGGGTCCGAGGTATTCGCACTGGATACGAC

CGCCAA-3' (Sangon Biotech, Shanghai, China), the reverse transcription primer for cel-miR-39 was $5^{\prime}$-GTCG TATCCAGTGCAGGGTCCGAGGTATTCGCAC TGGATACGACCAAGCTGA-3' (Sangon Biotech, Shanghai, China), and the reverse transcription primer for U6 was 5' - CGCTTCACGAATTTGCGTGTCAT-3' (Sangon Biotech, Shanghai, China).

\section{Quantitative real-time PCR}

Quantitative real-time PCR analyses were performed on a CFX connect system (Bio-Rad Laboratories) with Taq PCR Mix (Sangon Biotech, Shanghai, China). The following cycling conditions were used: $95^{\circ} \mathrm{C}$ for $150 \mathrm{~s} ; 40$ cycles of $95^{\circ} \mathrm{C}$ for $15 \mathrm{~s}, 60^{\circ} \mathrm{C}$ for $30 \mathrm{~s}$, and $72^{\circ} \mathrm{C}$ for $60 \mathrm{~s}$; followed by $72{ }^{\circ} \mathrm{C}$ for $10 \mathrm{~min}$. Three biological replicates were completed for all samples. The primers for hsamiR-1290 were as follows: forward, 5'-GCGCGTGGAT TTTTGGAT-3'; reverse, 5'-AGTGCAGGGTCCGAGG TATT-3'; and probe, 5'-FAM-CGCACTGGATACGA CTCCCT-TAMRA-N-3' (Sangon Biotech, Shanghai, China). The primers for hsa-miR-16-5p were as follows: forward, 5' - CGCGTAGCAGCACGTAAATA-3'; reverse, 5' - AGTGCAGGGTCCGAGGTATT - 3'; and probe, 5'-FAM-CGCACTGGATACGACCGCCTAMRA-N-3' (Sangon Biotech, Shanghai, China). The primers for cel-miR-39 were as follows: forward, $5^{\prime}$ GGCGTCACCGGGTGTAAA-3'; reverse, 5' - AGTG CAGGGTCCGAGGTATT-3'; and probe, 5'-FAMCAGCTTGGTCGTATCCAGTGCG-TAMRA-N-3'

(Sangon Biotech, Shanghai, China). The primers for U6 were as follows: forward, 5' - GCTTCGGCAGCACATA TACTAAAAT-3'; reverse, 5' - CGCTTCACGAATTT GCGTGTCAT-3'; and probe, 5'-FAM- CAGAGAAGATTAGCATGGCCCCTG-N-3' (Sangon Biotech, Shanghai, China). Finally, the expression level of miR1290 was analyzed using the $2^{-\Delta \Delta C t}$ method, with hsamiR-16-5p and cel-miR-39 serving as internal and exogenous controls, respectively.

\section{In vivo xenograft mouse model}

Female BALB/C nude mice at 4-6 weeks of age and weighing $18-20 \mathrm{~g}$ were purchased from the Shanghai 
Experimental Animal Center of the Chinese Academy of Sciences. The Ethics Committee of the Second Affiliated Hospital of Zhejiang University School of Medicine approved the animal experiments. HT29 cells in the logarithmic growth phase were collected, adjusted to a density of $2.5 \times 10^{7}$ cells $/ \mathrm{ml}$, and injected into the subcutaneous tissue of nude mice at a volume of $0.1 \mathrm{ml}$ per mouse. Overall, 15 mice were randomly divided into three groups with 5 mice in per group (the control group, the tumorigenic group without 5-FU treatment, and the tumorigenic group with 5-FU treatment) and raised in a specific-pathogen-free (SPF) environment. Animals in the two experimental groups were inoculated with tumor cells. After 1 week, when the xenografted tumors had grown to a certain size (approximately 100 $\mathrm{mm}^{3}$ ), animals in one group were intraperitoneally injected with 5 -FU $\left(20 \mathrm{mg} \cdot \mathrm{kg}^{-1} \cdot \mathrm{d}^{-1}\right)$ every 3 days, while animals in the other group were treated with the same amount of saline. The length and width of the tumors were measured every 3 days by a researcher who was unaware of the group allocation until the experiment was ended. The tumor volume $(\mathrm{V})$ was calculated using the following formula: $\mathrm{V}=$ length $/ 2 \times$ width $^{2}$. The mice were placed in a $10 \mathrm{~L}$ chamber with $99 \% \mathrm{CO}_{2}(3 \mathrm{~L} / \mathrm{min})$ for 5-10 min, and vital signs (including breath, heartbeat, and muscular tension) were closely monitored until death was confirmed. Serum samples were collected, and circulating miR-1290 levels were verified by RT-qPCR.

\section{Hematoxylin and eosin (H\&E) staining}

Tissue specimens were incubated in $10 \%$ formaldehyde for $48 \mathrm{~h}$ and then stored in ethanol and embedded in paraffin. The tissue blocks were cut into 4- $\mu \mathrm{m}$ sections and stained with H\&E (BASO). Slides were observed under a microscope (Olympus, Japan) and the following features were used to recognize tumor cells: architectural atypia, hyperchromasia, condensed and fractured chromatin, increased mitotic figures and nuclei migration to the edge.

\section{Statistical analysis}

Descriptive statistical analyses were performed to summarize the clinical features of patients. Quantitative data are presented as the mean \pm standard deviation. The chi-square test was used to analyze the associations between miR-1290 expression and clinicopathological characteristics. Differences between two independent groups were assessed using Student's t test. Comparisons among multiple groups were conducted using one-way analysis of variance (ANOVA). The sample size was calculated using the PASS software (version 11.0.7). The charting and statistical analyses were performed using GraphPad Prism (version 8.0.2) and SPSS (version 23.0) software. A $p$ value of 0.05 or less was defined as statistically significant $\left(*, p<0.05,{ }^{* * *}, p<0.01\right.$, and ${ }^{* * * *}$, $p<0.001)$.

\section{Results Up-regulation of miR-1290 in tumor tissues and serum from patients with CRC}

Our previous study confirmed a substantial increase in miR-1290 expression in tumor tissues from patients with CRC and demonstrated that the up-regulation of miR1290 impaired cytokinesis and affected the reprogramming of colon cancer cells. Therefore, miR-1290 plays an important role in CRC progression. We collected 10 pairs of tumor tissues and adjacent tissues to further verify the expression level of miR-1290 in CRC and found that miR-1290 was significantly overexpressed in tumor tissues (Fig. 1a).

Three pairs of serum samples from patients with CRC and controls matched for clinical characteristics, such as age, sex, and the past history, were selected for the miRNA sequencing analysis. We took the Venn intersection of the commonly and differentially expressed miRNAs in different groups. As shown in Fig. 1b, 223 (24.9\%) miRNAs were only detected in the control group, 139 (15.5\%) miRNAs were only detected in the CRC group, and 534 (59.6\%) miRNAs were detected in both groups. In total, 656 differentially expressed miRNAs were detected in serum samples from patients with CRC, compared with samples from healthy controls; among them, 261 miRNAs were up-regulated and 395 miRNAs were down-regulated $(p<0.01)$. The miRNAs with very low expression levels were excluded, and a volcano graph analysis was performed. Compared with the control group, 94 miRNAs were up-regulated and 104 miRNAs were down-regulated in patients with CRC $(|\log 2 \mathrm{FC}|>1, p<0.01)$ (Fig. 1c). Based on the miRNA expression profiles, differentially expressed miRNAs with high expression levels were chosen for cluster analysis. As shown in the heatmap, hsa-miR-1290 was significantly overexpressed in serum from patients with CRC (Fig. 1d), suggesting that miR-1290 might be a potential biomarker for gastrointestinal tumors.

In addition, 16 CRC-associated miRNAs were identified $(\mathrm{FC}>3)$, as listed in Table S1. The potential target genes for these miRNAs were predicted using TargetScan and MiRanda, and 2646 target genes were finally predicted. To further understand the biological function of the identified target genes, GO and KEGG pathway enrichment analysis was performed by DAVID. As shown in Figure S1A-B, the Biological Process (BP) of target genes mainly focused on the Golgi vesicle transport, dephosphorylation, and protein localization to cell periphery. The Cellular Component (CC) of target genes were concentrated in synaptic membrane, cell-substrate adherens junction, and trans-Golgi network. The 

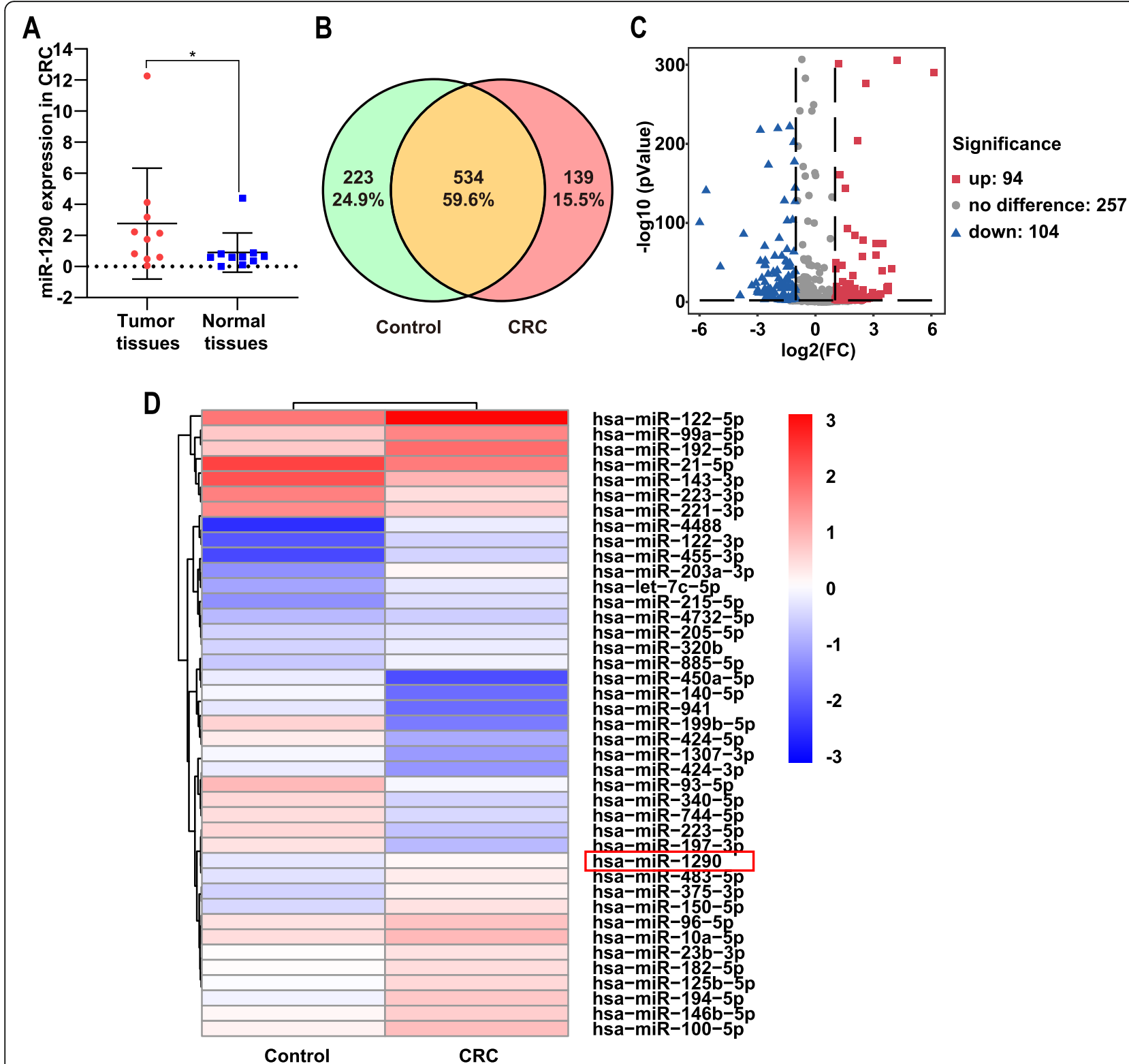

Fig. 1 miR-1290 was upregulated in the tumor tissue and serum of patients with CRC. a Expression of miR-1290 in tumor tissues and paired normal tissues $(n=10)$. miR-1290 was significantly overexpressed in tumor tissues $(p<0.05)$. $\mathbf{b}$ Venn diagram of the commonly and differentially expressed miRNAs in different groups. 223 (24.9\%) miRNAs were only detected in the control group, 139 (15.5\%) miRNAs were only detected in the CRC group, and 534 (59.6\%) miRNAs were detected in both groups. c Volcano plot of differentially expressed miRNAs. Two hundred sixty-one miRNAs were up-regulated and 395 miRNAs were down-regulated in serum samples from patients with CRC. $(p<0.01, \| \log 2 \mathrm{FC} \mid>1)$. c Heatmaps of cluster analysis for differentially expressed miRNAs with high expression levels $(p<0.01,|\log 2 \mathrm{FC}|>1)$. Blue color represents a lower expression level and red color represent a higher expression level. ${ }^{*} p<0.05$

Molecular Function (MF) of target genes mainly enriched in phosphatase activity, phosphoric ester hydrolase activity, and protein Serine/Threonine kinase activity. Besides, the propanoate metabolism was the most important item in KEGG pathway analysis. To explore the evolutionary conservation on these biomarkers, the phylogenetic tree was plotted using the $\mathrm{p}$ distance and the average method. As shown in Figure S1C, these miRNAs were significantly separated into three branches. Besides, to further explore the miRNA interaction, we established a miRNA-mRNA regulatory network with 16 miRNAs and 61 predicted target genes, as depicted in Figure S2.

\section{Establishment and evaluation of circulating miRNA detection technologies for clinical Identification} A reliable methodology was needed to analyze the circulating miR-1290 expression levels in clinical samples. 
First, we used different methods to extract circulating miRNAs, including three extraction kits from QIAGEN and two TRIzol reagents from Invitrogen, each with different extraction principles, as shown in Table S2. We examined the serum miR-1290 levels in 20 healthy individuals using cel-miR-39 or miR-16-5p as a reference miRNA (Table S3). We obtained different results when choosing different reference miRNAs, indicating the importance of an appropriate control. The extraction efficiency of the miRNeasy Serum/Plasma Kit, miRNeasy Serum/Plasma Advanced Kit and TRIzol LS was better than that of the other two methods. Because the miRNeasy Serum/Plasma Kit and miRNeasy Serum/Plasma Advanced Kit are manufactured by QIAGEN and the miRNeasy Serum/Plasma Advanced Kit produced better results than the miRNeasy Serum/Plasma Kit, we further compared the extraction efficiency of the miRNeasy Serum/Plasma Advanced Kit and TRIzol LS for cell-free miRNAs.

The influence of the reference miRNA was eliminated by adding the same amount of cel-miR-39 $(10 \mu \mathrm{M}, 5 \mu \mathrm{l})$ to the same volume of serum. For the same amount of circulating cel-miR-39, the extraction efficiency of the miRNeasy Serum/Plasma Advanced Kit was apparently higher than that of TRIzol LS (Fig. 2a, $p<0.0001$ ). Therefore, the miRNeasy Serum/Plasma Advanced Kit was chosen as the main method for subsequent experiments.

We tested miR-1290 standards at different concentrations $(100 \mathrm{nM}, 10 \mathrm{nM}, 1 \mathrm{nM}, 100 \mathrm{pM}, 10 \mathrm{pM}, 1 \mathrm{pM}, 0.1$ $\mathrm{pM})$ and drew a standard curve $(\mathrm{y}=-4.173 \mathrm{x}+58.96$, $\left.R^{2}=0.9998\right)$ to further evaluate the recovery efficiency of the entire circulating miRNA detection system (Fig. 2b). Then, standard solutions of low, middle, and high concentrations were added to the sample solutions and analyzed in the same manner. The miRNA concentration in the sample was calculated from the standard curve, and the recovery rate was evaluated. The recovery efficiency in the three groups with a low, middle, and high standard concentration was 103,116 , and $87.8 \%$, respectively (Table S4), which was within the acceptable range. The effect of interfering factors in the serum was also evaluated. We collected three samples with a high bilirubin, triglycerides, or rheumatoid factor level, and analyzed the recovery efficiency as described above. The recovery efficiency in the three groups was 119, 93.0, and 107\%, respectively (Table S4), which was within the acceptable range of error. Therefore, the serum level of bilirubin,

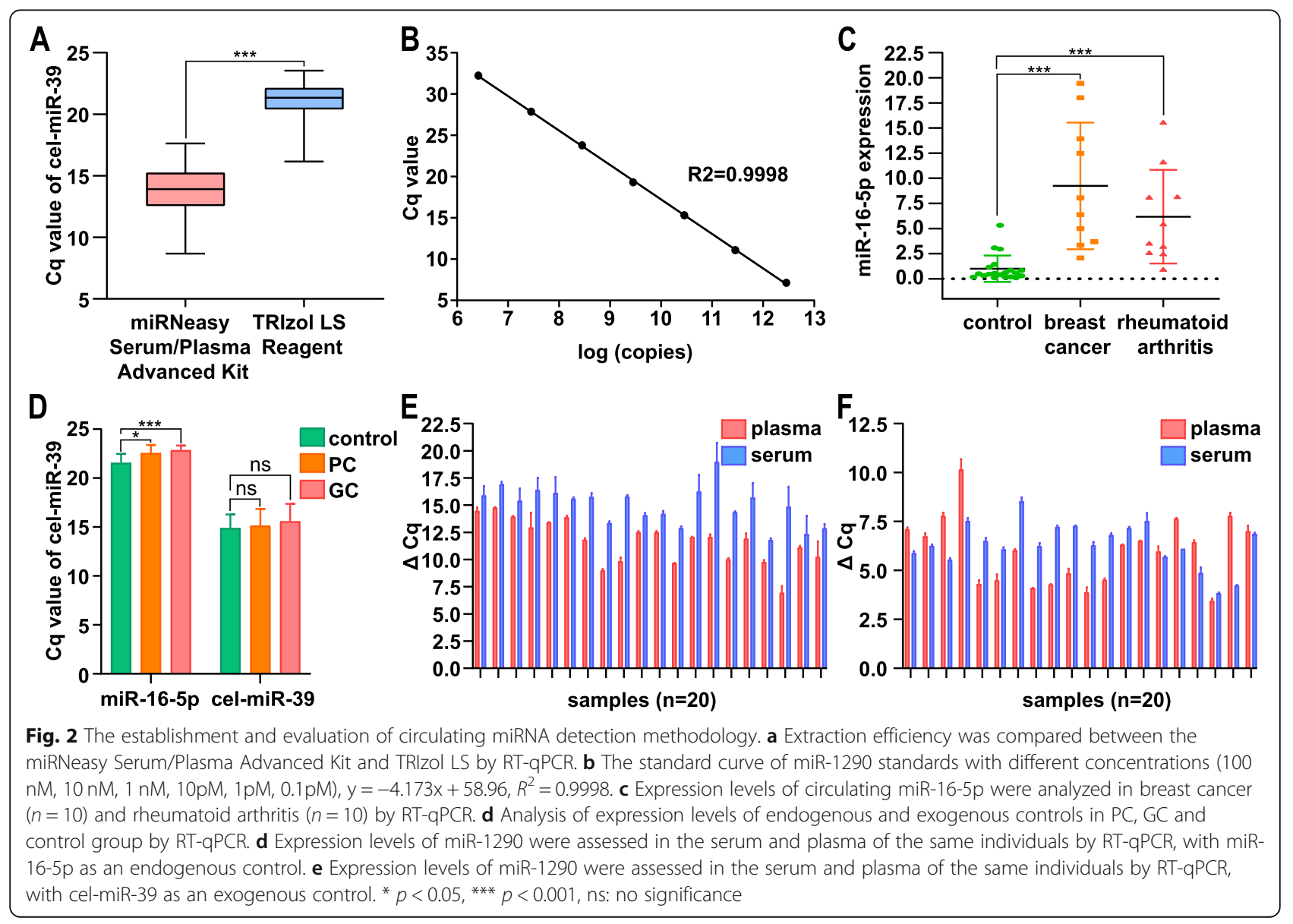


triglycerides, and rheumatoid factor did not interfere with the miRNA detection method.

Notably, miR-16-5p is a commonly used internal control for circulating miRNA detection. Previous studies have shown that miR-16-5p was overexpressed in breast cancer, chronic lymphocytic leukemia, rheumatoid arthritis, and other diseases. We collected serum samples from patients with different diseases, and evaluated miR-16-5p expression using cel-miR-39 as an exogenous control to verify the reliability of miR-16-5p as an internal control (Fig. 2c). The serum level of miR-16-5p in patients with breast cancer and patients with rheumatoid arthritis was significantly higher than that in healthy controls $(p<0.001)$. We also analyzed the $\mathrm{Cq}$ value of miR-16-5p and celmiR-39 in patients with PC, patients with GC, and healthy controls. The results were shown in Fig. $2 \mathrm{~d}$. The Cq value of miR-16-5p in patients with $P C$ and GC was much higher than that in healthy controls, while no significant difference in the Cq value of celmiR-39 was observed, indicating that miR-16-5p expression fluctuates in gastrointestinal tumors and is not suitable for use as an internal control.

In the final part of the methodological evaluation, we collected plasma and serum samples from 20 healthy individuals, to evaluate the difference in miR-1290 expression between serum and plasma samples from the same individual (Fig. 2e-f). We observed higher miR-1290 expression in plasma than in serum when cel-miR-39 was used as the reference miRNA. In contrast, in some individuals, the expression of miR-1290 was higher in serum than in plasma when miR-16-5p was used as the reference miRNA, which also indicated that miR-16-5p was not a reliable internal control.

\section{Human gastrointestinal tumor cells express and secrete miR-1290}

We examined the expression of miR-1290 in human gastrointestinal tumor cell lines to clarify the source of circulating miR-1290. As shown in Fig. 3a, five CRC cell lines including HT29, HCT116, P4, SW480, and SW620, three PC cell lines including ASPC-1, BXPC-3, and SW1990, and two GC cell lines including SGC7901 and BGC823 were analyzed. The expression level of miR1290 was lower in GC cell lines than in CRC and PC cell lines. The lowest miR-1290 expression level was observed in BGC823 cells, while miR-1290 was expressed at relatively high levels in HT29, HCT116, P4, ASPC-1, and BXPC-3 cells. We further examined miR-1290 expression in the culture supernatant of the five cell lines (HT-29, HCT116, ASPC-1, BXPC-3, and SGC7901) when cultured at different cell densities for 24, 48, and $72 \mathrm{~h}$. As shown in Fig. 3b-f, gastrointestinal tumor cells expressed and secreted miR-1290 into the culture supernatant, and the miR-1290 expression level in the culture supernatant increased with both cell density and culture time. Therefore, circulating miR-1290 might be derived from tumor cells and secreted as a potential tumor biomarker.

\section{Circulating miR-1290 serves as a diagnostic biomarker for gastrointestinal tumors}

In the subsequent validation phase, the circulating miR1290 expression level was detected in 46 patients with PC, 50 patients with CRC, 50 patients with GC, and 50 healthy controls. The clinical characteristics of the participants were summarized in Table 1. Significant differences in sex, BMI, smoking history, or alcohol consumption were not observed between the PC and the control group. Patients in the PC group were older $(p<$ $0.05)$ and a higher proportion of patients in this group had hypertension $(p<0.05)$ and diabetes $(p<0.05)$. Furthermore, the CEA $(p<0.001)$, CA199 $(p<0.001)$, CA125 $(p<0.001)$, CA242 $(p<0.001)$, and CA211 $(p<$ $0.01)$ levels in the PC group were significantly higher than those in the control group. No significant variations in age, sex, BMI, alcohol consumption or diabetes history were observed between the CRC and the control group, but the ratio of smokers $(p<0.05)$ and patients with hypertension $(p<0.05)$ was much higher in the CRC group than in the control group. The CEA level $(p<0.001)$ in the CRC group was apparently higher than that in the control group, while the expression levels of the other biomarkers were similar in the CRC and the control group. In addition, no significant differences in age, sex, BMI, smoking history, alcohol consumption, hypertension history, or diabetes history were observed between the GC and the control group. CEA expression was higher in the GC group $(p<0.01)$ while the remaining biomarkers showed no significant difference in expression between the GC and the control group.

As shown in Fig. 4a-c, the expression level of circulating miR-1290 considerably increased in patients with PC $(p<0.01)$, CRC $(p<0.05)$, and GC $(p<0.01)$. Correlations between the serum miR-1290 expression level and clinicopathological characteristics of patients with gastrointestinal cancer were explored. In patients with PC (Table 2), significant correlations were not observed between the circulating miR-1290 level and age, sex, BMI, smoking history, alcohol consumption, hypertension history, diabetes history, or tumor site. High miR1290 expression was associated with tumor size $(p<$ $0.01)$, lymphatic invasion $(p<0.01)$, vascular invasion $(p<0.05)$, distant metastasis $(p<0.05)$, tumor differentiation $(p<0.05)$, and tumor AJCC stage $(p<0.05)$. However, no significant correlations were observed between the circulating miR-1290 expression level and the levels of other tumor biomarkers, including CEA, CA199, 


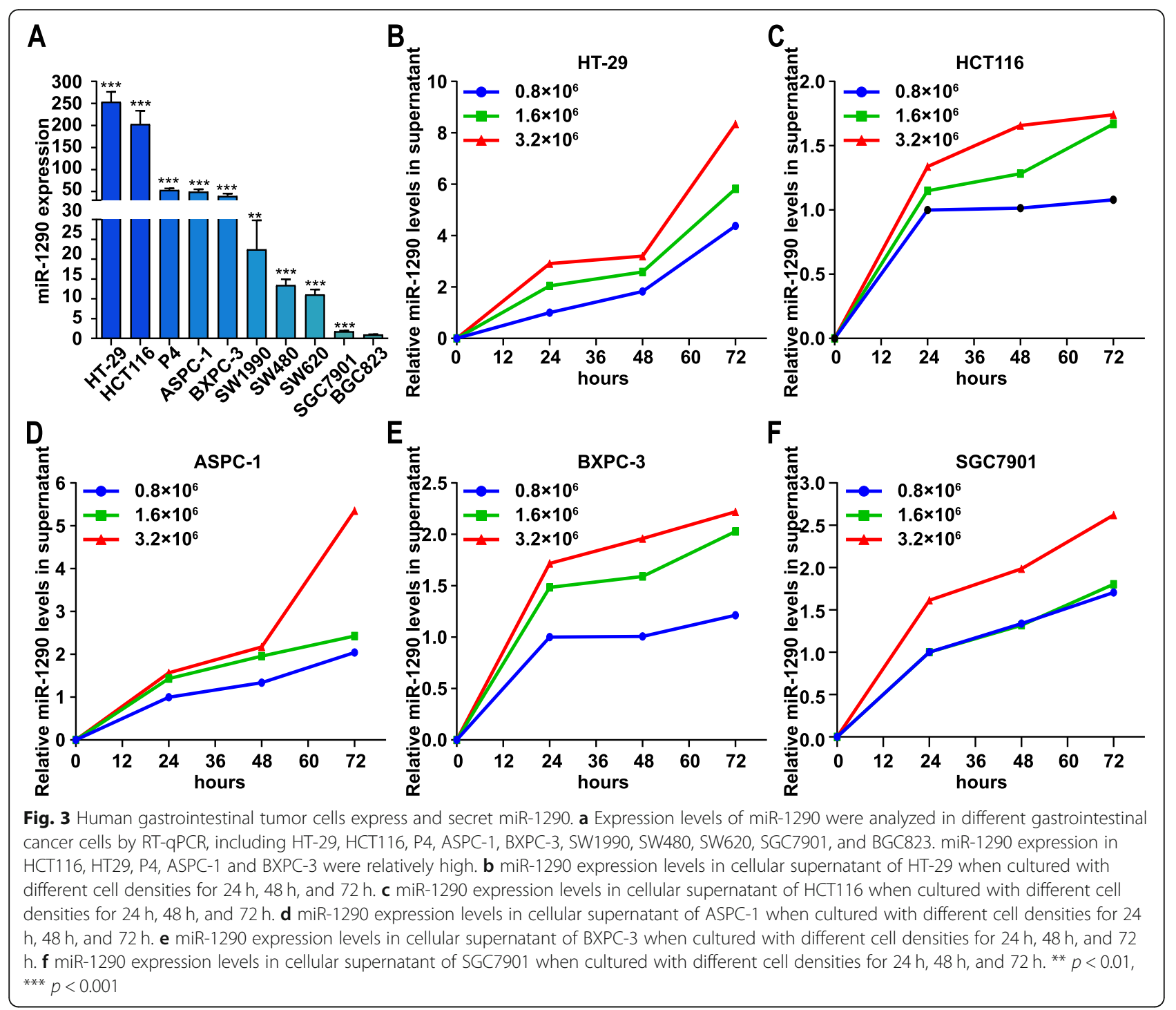

CA125, CA242, and CA211. In patients with CRC (Table 3), no clear associations were identified between the circulating miR-1290 expression levels and age, sex, BMI, smoking history, alcohol consumption, hypertension history, diabetes history, or tumor site. Significantly higher circulating miR-1290 levels were detected in CRC patients with larger tumors $(p<0.05)$, lymphatic invasion $(p<0.05)$, vascular invasion $(p<0.05)$, distant metastasis $(p<0.05)$, poorer tumor differentiation $(p<0.05)$, and more advanced AJCC stages $(p<0.05)$. The miR-1290 expression level was related to the CEA level $(p<0.05)$, while a significant correlation was not observed with the level of CA199, CA125, CA242, or CA211. In patients with GC (Table 4), significant correlations between the circulating miR-1290 expression level and age, sex, BMI, smoking, drinking, diabetes, or tumor location were not observed. The tumor size, lymphoid invasion, vascular invasion, distant metastasis, tumor differentiation degree, and the AJCC stage, as well as the levels of common tumor markers, also showed no remarkable correlation with circulating miR-1290 expression.

A receiver operating characteristic (ROC) curve analysis was performed to evaluate the potential diagnostic value of the circulating miR-1290 level. The area under the curve (AUC) was $0.8857(p<0.0001)$ in patients with PC, with $60.9 \%$ sensitivity and $90.0 \%$ specificity. The AUC was $0.7852(p<0.0001)$ for circulating miR-1290 in patients with CRC, with a sensitivity of $42.0 \%$ and specificity of $90.0 \%$. In patients with GC, the AUC of miR1290 was $0.6576(p<0.01)$, with a sensitivity of $26.0 \%$ and specificity of $90.0 \%$. Moreover, as shown in Fig. 4g-i, the combination of circulating miR-1290 and traditional biomarkers had higher diagnostic value. In patients with PC, the sensitivity and specificity of miR-1290 combined 
Table 1 Clinical characteristics of patients included in the study

\begin{tabular}{|c|c|c|c|c|c|c|c|}
\hline \multirow[t]{2}{*}{ Groups } & \multirow{2}{*}{$\begin{array}{l}\text { Control } \\
(n=50)\end{array}$} & \multicolumn{2}{|l|}{ Group $1(n=46)$} & \multicolumn{2}{|l|}{ Group $2(n=50)$} & \multicolumn{2}{|l|}{ Group $3(n=50)$} \\
\hline & & Pancreatic cancer & $p$ value & Colorectal cancer & $p$ value & Gastric cancer & $p$ value \\
\hline Age (year) & & & $0.016^{*}$ & & 0.102 & & 0.151 \\
\hline$<65 y$ & 34 & 20 & & 26 & & 27 & \\
\hline$\geq 65 y$ & 16 & 26 & & 24 & & 23 & \\
\hline Sex & & & 0.084 & & 0.105 & & 0.841 \\
\hline Male & 25 & 31 & & 33 & & 26 & \\
\hline Female & 25 & 15 & & 17 & & 24 & \\
\hline BMI $\left(\mathrm{kg} / \mathrm{m}^{2}\right)$ & & & 0.524 & & 0.832 & & 0.663 \\
\hline$<25$ & 34 & 34 & & 33 & & 36 & \\
\hline$\geq 25$ & 16 & 12 & & 17 & & 14 & \\
\hline Smoke & & & 0.167 & & $0.021 *$ & & 0.817 \\
\hline Yes & 12 & 17 & & 23 & & 13 & \\
\hline No & 38 & 29 & & 27 & & 37 & \\
\hline Alcohol & & & 0.478 & & 0.817 & & 1.000 \\
\hline Yes & 12 & 14 & & 13 & & 12 & \\
\hline No & 38 & 32 & & 37 & & 38 & \\
\hline Hypertension & & & $0.013^{*}$ & & $0.047^{*}$ & & 0.727 \\
\hline Yes & 10 & 20 & & 19 & & 12 & \\
\hline No & 40 & 26 & & 31 & & 38 & \\
\hline Diabetes & & & $0.022^{*}$ & & 1.000 & & 0.629 \\
\hline Yes & 5 & 13 & & 5 & & 4 & \\
\hline No & 45 & 33 & & 45 & & 46 & \\
\hline CEA (ng/ml) & & & $<0.0001^{* * *}$ & & $<0.0001 * * *$ & & $<0.006^{* *}$ \\
\hline$<5$ & 50 & 30 & & 33 & & 43 & \\
\hline$\geq 5$ & 0 & 16 & & 17 & & 7 & \\
\hline CA199 (U/ml) & & & $<0.0001^{* * *}$ & & 0.617 & & $<0.617$ \\
\hline$<37$ & 39 & 6 & & 41 & & 41 & \\
\hline$\geq 37$ & 11 & 40 & & 9 & & 9 & \\
\hline CA125 (U/ml) & & & $<0.0001^{* * *}$ & & 0.169 & & $<0.137$ \\
\hline$<35$ & 46 & 24 & & 49 & & 41 & \\
\hline$\geq 35$ & 4 & 22 & & 1 & & 9 & \\
\hline CA242 (U/ml) & & & $<0.0001^{* * *}$ & & 0.558 & & $<0.169$ \\
\hline$<20$ & 49 & 16 & & 48 & & 46 & \\
\hline$\geq 20$ & 1 & 30 & & 2 & & 4 & \\
\hline CA211 (ng/ml) & & & $0.001^{* *}$ & & 0.307 & & 0.092 \\
\hline$<5$ & 49 & 34 & & 47 & & 45 & \\
\hline$\geq 5$ & 1 & 12 & & 3 & & 5 & \\
\hline
\end{tabular}

with CA199 was 80.4 and $90.0 \%$, respectively, with an AUC of $0.9626(p<0.0001)$. In patients with CRC, the sensitivity and specificity of miR-1290 combined with CEA was 58.0 and $90.0 \%$, respectively, with an AUC of $0.8348(p<0.0001)$. The sensitivity and specificity of
miR-1290 combined with CA211 was 38.0 and $90.0 \%$ in patients with GC, with an AUC of $0.7788(p<0.0001)$. As a result, miR-1290 may represent a potential diagnostic biomarker for gastrointestinal cancer, with different diagnostic efficiencies for different types of tumors. 


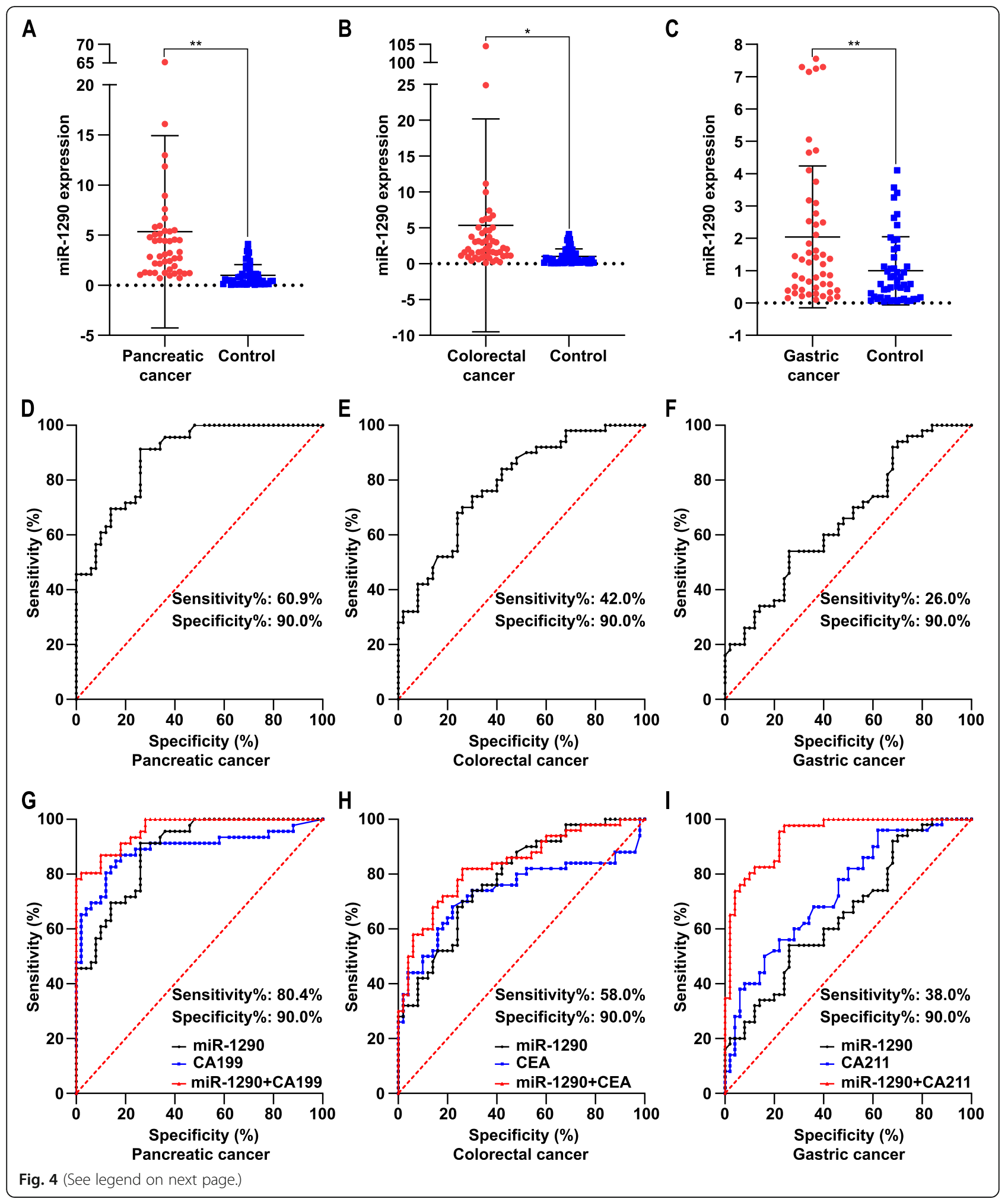


(See figure on previous page.)

Fig. 4 Circulating miR-1290 is a potential diagnostic biomarker in gastrointestinal tumors. a Serum miR-1290 expression levels in PC patients $(n=$ 46) and healthy controls $(n=50)$ were analyzed by RT-qPCR. b Serum miR-1290 expression levels in CRC patients $(n=50)$ and healthy controls ( $n=50)$ were analyzed by RT-qPCR. c serum miR-1290 expression levels in GC patients $(n=50)$ and healthy controls $(n=50)$ were analyzed by RTqPCR. d Circulating miR-1290 yielded AUC value of 0.8857 with $67.4 \%$ sensitivity and $90.0 \%$ specificity in distinguishing PC patients from healthy controls $(p<0.001)$. e Circulating miR-1290 yielded AUC value of 0.7852 with $48.0 \%$ sensitivity and $90.0 \%$ specificity in distinguishing CRC patients from healthy controls $(p<0.001)$. f Circulating miR-1290 yielded AUC value of 0.6576 with $34.0 \%$ sensitivity and $90.0 \%$ specificity in distinguishing GC patients from healthy controls $(p<0.001)$. g Sensitivity and specificity of circulating miR-1290 combined with CA199 were 80.4 and $90.0 \%$ with the AUC value of 0.9626 in PC $(p<0.0001)$. $\mathbf{h}$ Sensitivity and specificity of circulating miR-1290 combined with CEA were 58.0 and $90.0 \%$ with the AUC value of 0.8348 in CRC $(p<0.0001)$. i Sensitivity and specificity of circulating miR-1290 combined with CA211 were 38.0 and $90.0 \%$ with the AUC value of 0.7788 in PC $(p<0.0001)$. ${ }^{*} p<0.05,{ }^{* *} p<0.01$

\section{miR-1290 is a potential biomarker for gastrointestinal tumor surveillance}

A subcutaneous xenograft model of $\mathrm{CRC}$ in nude mice was constructed to evaluate the fluctuation in the circulating miR-1290 level during disease progression and drug treatment. Eight days after cell inoculation, the tumors grew to about $100 \mathrm{~mm}^{3}$ and were treated with 5FU or the same amount of saline, respectively. As shown in Fig. 5a, the tumor growths in 5-FU-treated group were significantly inhibited. Tumors of the saline group had larger volumes and weights than those of the 5-FU group $(p<0.01)$ (Fig. 5b-c). The circulating miR-1290 level increased significantly after tumor formation $(p<$ 0.001) (Fig. 5e). After treatment with 5-FU, the tumor tissue structure was destroyed and tumor cells were largely necrotic (Fig. 5d), with a remarkable reduction in the circulating miR-1290 level $(p<0.05)$ (Fig. 5e). Furthermore, we explored the changes in miR-1290 expression in 10 patients with CRC after surgery. As shown in Fig. 5f, circulating miR-1290 expression decreased substantially after surgery $(p<0.05)$. Therefore, circulating miR-1290 is a promising biomarker for gastrointestinal tumor surveillance.

\section{Discussion}

In this study, we identified circulating miR-1290 as an effective biomarker for the early diagnosis and monitoring of gastrointestinal tumors. Based on previous studies, we further confirmed that miR-1290 was up-regulated in tumor tissues and serum from patients with CRC. High miR-1290 expression was detected in various gastrointestinal cancer cell lines (PC, CRC, and GC), and miR1290 was released into the culture supernatant. The diagnostic efficiency of the circulating miR-1290 level was evaluated in patients with PC, CRC, and GC by establishing a reliable detection method for cell-free miRNAs. The results indicated that circulating miR-1290 is a potential biomarker for gastrointestinal tumors and that high miR-1290 expression is significantly correlated with disease progression.

Valuable early screening and monitoring indicators can improve patient prognosis and reduce the risk of over-treatment resulting from overdiagnosis [3].
Compared with cellular RNA species, circulating miRNAs are highly stable during long-term storage and extreme conditions, including boiling, multiple freeze-thaw cycles, RNase treatment, and high or low pH [8], making the evaluation of circulating miRNAs an essential part of liquid biopsy [9]. As shown in our previous study, miR1290 is up-regulated in CRC tissue and plays a crucial role in cancer progression [10]. According to previous studies, miR-1290 exerts a tumor-promoting effect and is involved in the occurrence and development of various tumors, such as CRC [11] and esophageal cancer [12]. In gastric cancer, miR-1290 was highly expressed and promoted cell proliferation and metastasis [13], it might be a potential exosome-based biomarker [14]. Ang Li et al. found that elevated serum miR-1290 accurately distinguished low stage pancreatic patients with healthy controls [15]. Serum miR-1290 might be a promising biomarker for diagnosis of pancreatic cancer [16]. Furthermore, miRNA sequencing indicated that miR-1290 is expressed at high levels in the serum of patients with CRC, suggesting that it might represent a potential gastrointestinal tumor marker.

Cell-free miRNA detection technology is maturing, but many problems still remain to be solved before its clinical application. For example, a high extraction efficiency should be guaranteed due to the relatively low concentration of circulating miRNA, the integrity of miRNA and the stability of detection. Particularly, when a single miRNA is chosen as a clinical biomarker, verification of pre-analysis steps affecting miRNA quantification is critically important. Although highly up-regulated or downregulated miRNAs have advantages as biomarkers, the clinical value of most markers depends on solving the fore-mentioned problems. However, many researches have not performed methodological verification [17]. Considering the difference between miRNA expression and the molecular mechanism, a detection method applicable to one study is not necessarily suitable for another. Consequently, the detection methodology (reliability, repeatability, and accuracy) for a specific miRNA must be verified and improved [18].

We selected the extraction kit with the highest extraction efficiency (miRNeasy Serum/Plasma Advanced Kit) 
Table 2 Association between circulating miR-1290 expression and clinicopathologic characteristics in 46 pancreatic cancer patients

\begin{tabular}{|c|c|c|c|c|}
\hline \multirow[t]{2}{*}{ Variable } & \multirow[t]{2}{*}{ Total $(n=46)$} & \multicolumn{2}{|c|}{ miR-1290 expression } & \multirow[t]{2}{*}{$p$ value } \\
\hline & & Low $(n=13)$ & High $(n=33)$ & \\
\hline Age (year) & $65.48 \pm 1.77$ & $69.15 \pm 3.53$ & $64.03 \pm 2.01$ & 0.195 \\
\hline Sex & & & & 0.975 \\
\hline Male & 32 & 9 & 23 & \\
\hline Female & 14 & 4 & 10 & \\
\hline $\mathrm{BMI}\left(\mathrm{kg} / \mathrm{m}^{2}\right)$ & $22.01(19.69-25.40)$ & $23.26(20.00-26.88)$ & $21.97(19.16-25.13)$ & 0.518 \\
\hline Smoke & & & & 0.057 \\
\hline Yes & 17 & 2 & 15 & \\
\hline No & 29 & 11 & 18 & \\
\hline Alcohol & & & & 0.164 \\
\hline Yes & 14 & 2 & 12 & \\
\hline No & 32 & 11 & 21 & \\
\hline Hypertension & & & & 0.818 \\
\hline Yes & 20 & 6 & 14 & \\
\hline No & 26 & 7 & 19 & \\
\hline Diabetes & & & & 0.813 \\
\hline Yes & 13 & 4 & 9 & \\
\hline No & 33 & 9 & 24 & \\
\hline Location & & & & 0.894 \\
\hline Head & 29 & 8 & 21 & \\
\hline Body and tail & 17 & 5 & 12 & \\
\hline Tumor size $(\mathrm{cm})$ & $3.55(2.32-4.53)$ & $2.30(1.80-2.80)$ & $4.00(2.87-4.60)$ & $0.002^{* *}$ \\
\hline Lymphatic invasion & & & & $0.003^{* *}$ \\
\hline Positive & 35 & 6 & 29 & \\
\hline Negative & 11 & 7 & 4 & \\
\hline Venous invasion & & & & $0.030^{*}$ \\
\hline Positive & 32 & 6 & 26 & \\
\hline Negative & 14 & 7 & 7 & \\
\hline Distant metastasis & & & & $0.022^{*}$ \\
\hline Positive & 23 & 3 & 20 & \\
\hline Negative & 23 & 10 & 13 & \\
\hline Differentiation & & & & $0.036^{*}$ \\
\hline Well & 7 & 3 & 4 & \\
\hline Moderate & 22 & 9 & 13 & \\
\hline Poor & 17 & 1 & 16 & \\
\hline TNM stage (AJCC) & & & & $0.022^{*}$ \\
\hline | and || & 23 & 10 & 13 & \\
\hline III and IV & 23 & 3 & 20 & \\
\hline CRP (mg/l) & & & & 0.624 \\
\hline$<10$ & 33 & 10 & 23 & \\
\hline$\geq 10$ & 13 & 3 & 10 & \\
\hline CEA (ng/ml) & & & & 0.295 \\
\hline$<5$ & 30 & 10 & 20 & \\
\hline$\geq 5$ & 16 & 3 & 13 & \\
\hline
\end{tabular}


Table 2 Association between circulating miR-1290 expression and clinicopathologic characteristics in 46 pancreatic cancer patients (Continued)

\begin{tabular}{|c|c|c|c|c|}
\hline \multirow[t]{2}{*}{ Variable } & \multirow[t]{2}{*}{ Total $(n=46)$} & \multicolumn{2}{|c|}{ miR-1290 expression } & \multirow[t]{2}{*}{$p$ value } \\
\hline & & Low $(n=13)$ & High $(n=33)$ & \\
\hline \multicolumn{5}{|l|}{ CA199 (U/ml) } \\
\hline$<37$ & 6 & 2 & 4 & 0.767 \\
\hline$\geq 37$ & 40 & 11 & 29 & \\
\hline CA125 (U/ml) & & & & 0.146 \\
\hline$<35$ & 24 & 9 & 15 & \\
\hline$\geq 35$ & 22 & 4 & 18 & \\
\hline CA242 (U/ml) & & & & 0.720 \\
\hline$<20$ & 16 & 4 & 12 & \\
\hline$\geq 20$ & 30 & 9 & 21 & \\
\hline CA211 (ng/ml) & & & & 0.299 \\
\hline$<5$ & 34 & 11 & 23 & \\
\hline$\geq 5$ & 12 & 2 & 10 & \\
\hline
\end{tabular}

as the main detection method for subsequent experiments among a variety of kits to ensure a high extraction efficiency. The main extraction principles of this kit are protein precipitation and silica technology, which reduce the inhibitory effects of interfering substances in the blood on the reverse transcription and PCR procedure. Then, we established a standard curve to analyze the recovery rate, which was within the acceptable error range and not affected by bilirubin, rheumatoid factor, or triglyceride in the serum. Thus, our method is reliable. In addition, standard normalization methods for circulating miRNA analyses are still lacking [19]. Notably, miR-16$5 p$ is a widely used endogenous control for circulating miRNA normalization [15]. As shown in previous studies, miR-16-5p is up-regulated in patients with numerous diseases, such as rheumatoid arthritis [20], breast cancer [21], and esophageal cancer [22], and serves as a potential disease marker. In our study, we also confirmed that miR-16-5p is overexpressed in the serum of patients with breast cancer and rheumatoid arthritis, the expression level of circulating miR-16-5p fluctuates with changes in disease activity in patients with gastrointestinal tumors, and normalization with miR-16-5p might decrease variability, as discovered in previous research [7]. Therefore, an external control (cel-miR-39) is preferred.

In the present study, the expression level of miR-1290 in the plasma was higher than that in the serum from the same individual. Contamination of blood cells and PCR amplification processes are the main factors affecting the results [23]. Circulating miRNAs are contaminated with miRNAs from blood cells during coagulation or the separation process of plasma, and hemolysis leads to the release of miRNA from red blood cells [24]. In addition, the anticoagulants and blood stabilizers used during plasma collection also affect the quantitation of circulating miRNAs [25]. The plasma collection process affects the recovery rate and accuracy, regardless of the miRNA expression level. Notably, high RNA concentrations can reduce the interference of plasma components in PCR quantification, indicating that, when cel-miR-39 is used as an exogenous control, the amount added should be maintained at an appropriate and consistent level. Catherine Foye et al also discovered that the results for the detection of endogenous and exogenous controls varied in the serum and plasma, with higher expression levels in plasma [26]. Therefore, the appropriate samples and standardized blood sample processing procedures must be selected to reduce the detection errors in clinical analysis.

Many commonly used biomarkers for malignant tumors of the digestive tract have a broad spectrum. We compared the expression level and diagnostic efficiency of miR-1290 in patients with PC, CRC, and GC to comprehensively understand the diagnostic value of miR1290 as a biomarker. Significantly higher miR-1290 expression was observed in patients with PC, CRC, and GC than in control, with the highest diagnostic efficiency observed in patients with PC. Previous studies have confirmed the diagnostic value of circulating miR1290 levels in patients with gastrointestinal tumors, for example, PC [15, 27], CRC [28, 29], and esophageal squamous-cell carcinoma [30]. However, these studies were all conducted in patients with one specific tumor and lacked an evaluation of the role of miR-1290 in different types of tumors. In our study, high miR-1290 expression in the serum was associated with tumor size, lymphatic invasion, venous invasion, distant metastasis, 
Table 3 Association between circulating miR-1290 expression and clinicopathologic characteristics in 50 colorectal cancer patients

\begin{tabular}{|c|c|c|c|}
\hline \multirow[t]{2}{*}{ Variable } & \multirow[t]{2}{*}{ Total $(n=50)$} & \multicolumn{2}{|c|}{ miR-1290 expression } \\
\hline & & Low $(n=23)$ & $\mathrm{Hi}$ \\
\hline Age (year) & $64.00 \pm 1.62$ & $63.26 \pm 2.46$ & 64 \\
\hline \multicolumn{4}{|l|}{ Sex } \\
\hline Male & 33 & 12 & 21 \\
\hline Female & 17 & 11 & 6 \\
\hline $\mathrm{BMI}\left(\mathrm{kg} / \mathrm{m}^{2}\right)$ & $23.83(21.33-25.54)$ & $24.24(20.96-27.64)$ & 23 \\
\hline \multicolumn{4}{|l|}{ Smoke } \\
\hline Yes & 23 & 10 & 13 \\
\hline No & 27 & 13 & 14 \\
\hline \multicolumn{4}{|l|}{ Alcohol } \\
\hline Yes & 13 & 6 & 7 \\
\hline No & 37 & 17 & \\
\hline
\end{tabular}

Hypertension

\begin{tabular}{ll} 
High $(\boldsymbol{n}=\mathbf{2 7})$ & $\begin{array}{l}\boldsymbol{p} \\
\text { value }\end{array}$ \\
\hline $64.63 \pm 2.19$ & 0.679 \\
& 0.057 \\
21 & \\
6 & \\
$23.36(21.45-25.24)$ & 0.483 \\
& 0.741
\end{tabular}

Yes

No

Diabetes

Yes

No

Location

$\begin{array}{ll}\text { colon } & 24 \\ \text { rectum } & 26\end{array}$

Tumor size $(\mathrm{cm})$

Lymphatic invasion

Positive

Negative

Venous invasion

Positive

Negative

Distant metastasis

Positive

Negative

Differentiation

Well

Moderate

Poor

TNM stage (AJCC)

$\begin{array}{ll}\text { I and II } & 25 \\ \text { III and IV } & 25\end{array}$

CRP (mg/l)

$<10$

$\geq 10$

CEA (ng/ml)

$<5$

$\geq 5$
19

31

\section{5}

45

\section{4}

26

$3.50(3.00-3.05)$

22

28

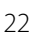

28

\section{6}

34

1

39

10

25

25
13

14

2

21

24

14

13

$4.00(3.00-5.00)$

$0.037^{*}$

$0.019 *$

6

17

16

11

6

17

4

19

15

8

17

19

4

19

14

13

$0.019^{*}$
0.041 *

$0.025^{*}$

0

18

9

$0.047^{*}$

10

22

5

16

15

8

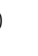

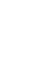

0.918

$0.022^{*}$ 
Table 3 Association between circulating miR-1290 expression and clinicopathologic characteristics in 50 colorectal cancer patients (Continued)

\begin{tabular}{|c|c|c|c|c|}
\hline \multirow[t]{2}{*}{ Variable } & \multirow[t]{2}{*}{ Total $(n=50)$} & \multicolumn{2}{|c|}{ miR-1290 expression } & \multirow{2}{*}{$\begin{array}{l}p \\
\text { value }\end{array}$} \\
\hline & & Low $(n=23)$ & High $(n=27)$ & \\
\hline CA199 (U/ml) & & & & 0.400 \\
\hline$<37$ & 41 & 20 & 21 & \\
\hline$\geq 37$ & 9 & 3 & 6 & \\
\hline CA125 (U/ml) & & & & 0.351 \\
\hline$<35$ & 49 & 23 & 26 & \\
\hline$\geq 35$ & 1 & 0 & 1 & \\
\hline CA242 (U/ml) & & & & 0.183 \\
\hline$<20$ & 48 & 23 & 25 & \\
\hline$\geq 20$ & 2 & 0 & 2 & \\
\hline CA211 (ng/ml) & & & & 0.650 \\
\hline$<5$ & 47 & 22 & 25 & \\
\hline$\geq 5$ & 3 & 1 & 2 & \\
\hline
\end{tabular}

differentiation, and TNM stage (AJCC) in patients with PC and CRC, while this relationship was not observed in patients with GC. The circulating miR-1290 level might be a potential marker for invasiveness and disease progression in patients with PC and CRC, while the correlation with the aggressiveness of GC was not strong. Patients with CRC with high miR-1290 expression levels also had relatively high CEA levels, while no association between the level of miR-1290 expression and that of other tumor markers was observed. In patients with $\mathrm{PC}$, correlations were not observed between the level of miR-1290 expression and that of other common biomarkers. Based on these results, the serum/plasm miR1290 level represents an independent biomarker with great value as a reference in diagnosing tumors and determining a patient's condition. We also explored the role of miR-1290 in disease monitoring. Based on the combination of data from clinical patients and the xenograft mouse models, we concluded that the circulating miR-1290 level fluctuated during tumor development and treatment, playing an important role in the realtime monitoring of tumor progression. Although similar studies have been conducted in the past, our study focused on the establishment and verification of the methodology and compared the efficiency of miR-1290 in diagnosing various gastrointestinal tumors. In addition, data from clinical samples and an animal model were combined to ensure the reliability of the results and the clinical significance of the research conclusions.

This study has several limitations. First, the sample size was small. A large sample size from a multicenter study is needed to further confirm the conclusions. Second, it would be more convincing to evaluate the role of circulating miR-1290 in other gastrointestinal tumors. Third, we have not explored the correlation between miR-1290 expression and patient prognosis. We plan to conduct a long-term clinical follow-up study to determine whether the circulating miR-1290 level can serve as a prognostic biomarker. In addition, previous studies have suggested that miR-1290 is involved in the regulation of chemotherapy resistance in a variety of tumors [31]. Ling Ye et al discovered that tissue miR-1290 expression levels were positively correlated with the dMMR status and predicted the prognosis of patients with CRC receiving 5-FU treatment [32]. The circulating miR-1290 level was also a potential biomarker for the response of patients with advanced oral squamous cell cancer to 5-FU-based chemoradiotherapy [33]. Therefore, the relationship between circulating miR-1290 expression and chemotherapy resistance in patients with gastrointestinal tumors is worthy further study. Furthermore, in-depth studies on the possible molecular mechanism are lacking. The ability of cancer cells to interconvert between epithelial and mesenchymal states was closely related to tumor progression [34-36]. The correlation between miR-1290 and epithelialmesenchymal plasticity (EMP) remains to be discussed [37-39]. Finally, the combined diagnosis using multiple different markers also have great research value.

\section{Conclusions}

We have established a reliable method for the detection of circulating miRNAs, and circulating miR-1290 is a potential biomarker for the diagnosis and monitoring of human gastrointestinal tumors. 
Table 4 Association between circulating miR-1290 expression and clinicopathologic characteristics in 50 gastric cancer patients.

\begin{tabular}{|c|c|c|c|c|}
\hline \multirow[t]{2}{*}{ Variable } & \multirow[t]{2}{*}{ Total $(n=50)$} & \multicolumn{2}{|c|}{ miR-1290 expression } & \multirow{2}{*}{$\begin{array}{l}p \\
\text { value }\end{array}$} \\
\hline & & Low $(n=33)$ & High $(n=17)$ & \\
\hline Age (year) & $63.74 \pm 1.62$ & $65.58 \pm 1.78$ & $60.18 \pm 3.19$ & 0.115 \\
\hline Sex & & & & 0.616 \\
\hline Male & 26 & 18 & 8 & \\
\hline Female & 24 & 15 & 9 & \\
\hline $\mathrm{BMI}\left(\mathrm{kg} / \mathrm{m}^{2}\right)$ & $22.33(20.50-25.11)$ & $22.27(20.38-25.06)$ & $22.48(20.49-25.50)$ & 0.690 \\
\hline Smoke & & & & 0.334 \\
\hline Yes & 13 & 10 & 3 & \\
\hline No & 37 & 23 & 14 & \\
\hline Alcohol & & & & 0.520 \\
\hline Yes & 12 & 7 & 5 & \\
\hline No & 38 & 26 & 12 & \\
\hline Hypertension & & & & $0.031 *$ \\
\hline Yes & 12 & 11 & 1 & \\
\hline No & 38 & 22 & 16 & \\
\hline Diabetes & & & & 0.134 \\
\hline Yes & 4 & 4 & 0 & \\
\hline No & 46 & 29 & 17 & \\
\hline Tumor size (cm) & $4.00(1.93-5.50)$ & $4.50(2.00-5.45)$ & $4.00(0.70-7.00)$ & 0.498 \\
\hline Lymphatic invasion & & & & 0.261 \\
\hline Positive & 29 & 21 & 8 & \\
\hline Negative & 21 & 12 & 9 & \\
\hline Venous invasion & & & & 0.370 \\
\hline Positive & 25 & 18 & 7 & \\
\hline Negative & 25 & 15 & 10 & \\
\hline Distant metastasis & & & & 0.613 \\
\hline Positive & 14 & 10 & 4 & \\
\hline Negative & 36 & 23 & 13 & \\
\hline Differentiation & & & & 0.526 \\
\hline Well & 9 & 5 & 4 & \\
\hline Moderate & 12 & 7 & 5 & \\
\hline Poor & 29 & 21 & 8 & \\
\hline TNM stage (AJCC) & & & & 0.754 \\
\hline | and || & 28 & 19 & 9 & \\
\hline III and IV & 22 & 14 & 8 & \\
\hline CRP (mg/l) & & & & 0.218 \\
\hline$<10$ & 47 & 32 & 15 & \\
\hline$\geq 10$ & 3 & 1 & 2 & \\
\hline CEA (ng/ml) & & & & 0.235 \\
\hline$<5$ & 43 & 27 & 16 & \\
\hline$\geq 5$ & 7 & 6 & 1 & \\
\hline CA199 (U/ml) & & & & 0.410 \\
\hline$<37$ & 41 & 26 & 15 & \\
\hline$\geq 37$ & 9 & 7 & 2 & \\
\hline
\end{tabular}


Table 4 Association between circulating miR-1290 expression and clinicopathologic characteristics in 50 gastric cancer patients. (Continued)

\begin{tabular}{|c|c|c|c|c|}
\hline \multirow[t]{2}{*}{ Variable } & \multirow[t]{2}{*}{ Total $(n=50)$} & \multicolumn{2}{|c|}{ miR-1290 expression } & \multirow{2}{*}{$\begin{array}{l}p \\
\text { value }\end{array}$} \\
\hline & & Low $(n=33)$ & High $(n=17)$ & \\
\hline CA125 (U/ml) & & & & 0.963 \\
\hline$<35$ & 41 & 27 & 14 & \\
\hline$\geq 35$ & 9 & 6 & 3 & \\
\hline CA242 (U/ml) & & & & 0.692 \\
\hline$<20$ & 46 & 30 & 16 & \\
\hline$\geq 20$ & 4 & 3 & 1 & \\
\hline CA211 (ng/ml) & & & & 0.486 \\
\hline$<5$ & 45 & 29 & 16 & \\
\hline$\geq 5$ & 5 & 4 & 1 & \\
\hline
\end{tabular}
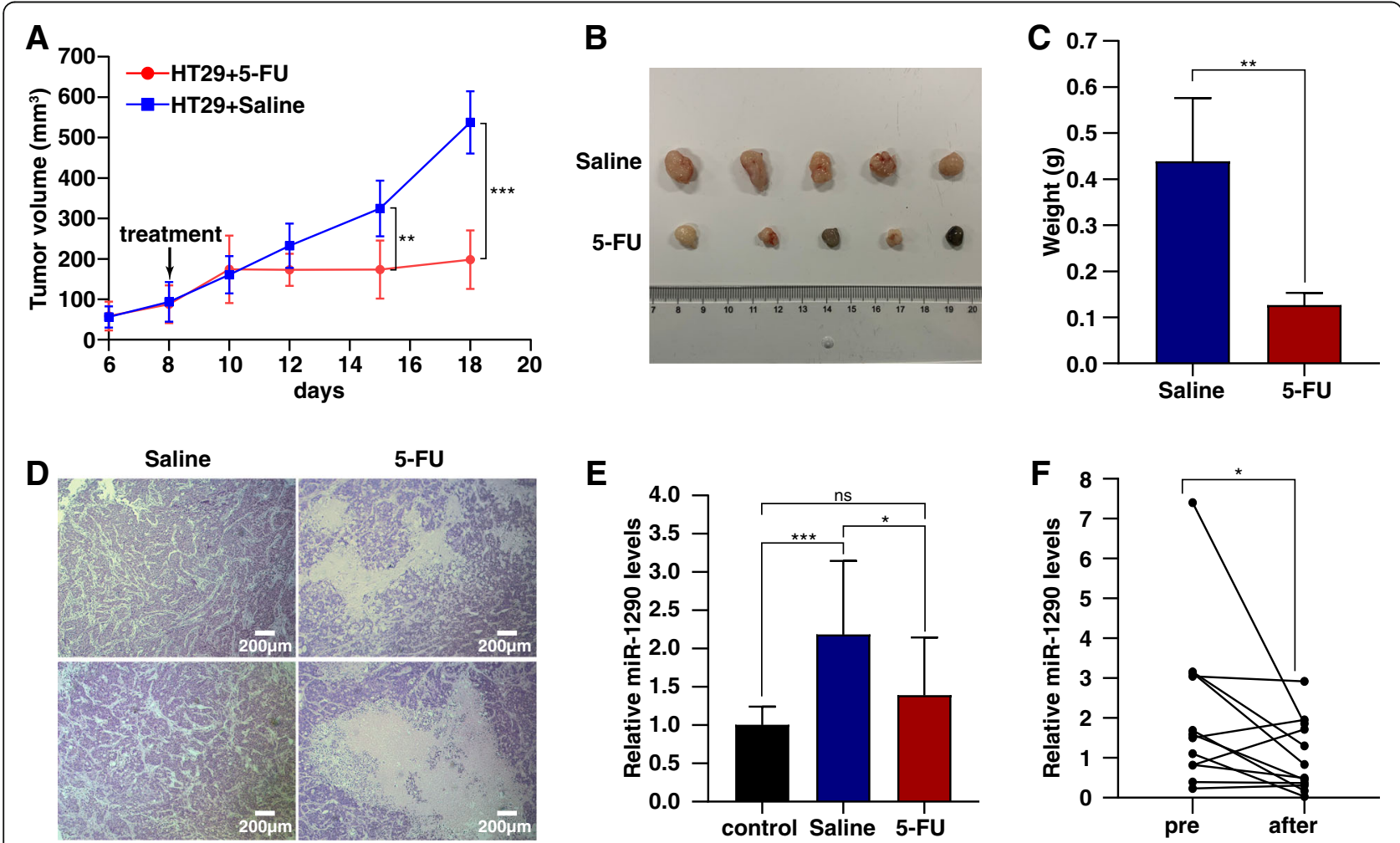

Fig. 5 Circulating miR-1290 is a promising biomarker for disease surveillance. a The tumor growth curve of different groups. Compared to the saline group, tumor growth in 5-FU-treated group was significantly inhibited. b Images of all tumors from nude mouse. Tumors in 5-FU group were significantly smaller than those in saline group. c Comparison of tumor weights between saline group and 5-FU group. Tumors in the saline group were heavier than those in the 5-FU group. $\mathbf{d}$ H\&E staining of tumors of saline and 5-FU group. The 5-FU group exhibited a large degree of cell apoptosis and necrosis. e The fluctuation of circulating miR-1290 during disease progression and drug treatment in the xenograft mouse model. $\mathbf{f}$ Changes of serum miR-1290 levels in CRC patients after surgery were determined by RT-qPCR $(n=10) .{ }^{*} p<0.05,{ }^{* *} p<0.01$,

${ }^{* * *} p<0.001$ 


\section{Abbreviations}

CRC: Colorectal cancer; PC: Pancreatic cancer; GC: Gastric cancer; ROC curve: Receiver operating characteristic curve; AUC: Area under the curve

\section{Supplementary Information}

The online version contains supplementary material available at https://doi. org/10.1186/s12885-021-08729-0.

\section{Additional file 1 : Table S1. Highly expressed serum miRNAs in}

patients with CRC compared to normal controls. Table S2. Different RNA extraction technologies utilized in this study. Table S3. Mean $C_{q}$ values and SD of circulating miR-1290 measured by RT-qPCR in 20 healthy individuals with different RNA extraction methods. Table S4. Recovery efficiency and the influence of common interference factors. Fig. S1.

Functional enrichment analysis of target genes and phylogenetic analysis of miRNAs. (a-b) GO term enrichment analysis and KEGG pathway analysis of target genes. Top three terms with FDR $<0.01$. (c) The phylogenetic tree of miRNAs shown in Table S1 based on the p distance and the average method. Fig. S2. The interaction regulatory network of the selected upregulated miRNAs and downregulated target mRNAs. The red circle represents miRNA, and the blue rectangle represents the target genes.

\section{Acknowledgements}

Thanks for the experimental platform provided by the Institute of Cancer, the Second Affiliated Hospital, College of Medicine of Zhejiang University.

\section{Authors' contributions}

All authors have accepted responsibility for the entire content of this manuscript and approved its submission. XLY designed the study, performed the experiments, and wrote the paper, CYK and CX collected the clinical samples and helped with data analysis, ZYL and CJT provided resources and revised the manuscript.

\section{Funding}

This work was supported by funding from the Science Technology Department of Zhejiang Province (2014C03041-1), National Key R\&D Program of China (Grant No.2016YFC1303200), and the National Natural Science Foundation of China (82073160). The funders mainly provided support in sample collection, analysis, and interpretation of data.

\section{Availability of data and materials}

The datasets generated and/or analyzed during the current study are available in the Sequence Read Archive (SRA) repository (https://www.ncbi. nlm.nih.gov/Traces/study/?acc=PRJNA756902). Accession number: PRJNA756902.

\section{Declarations}

\section{Ethics approval and consent to participate}

The research related to human use has been complied with all the relevant national regulations, institutional policies and in accordance the tenets of the Helsinki Declaration, and has been approved by the Ethics Committee of the Second Affiliated Hospital of Zhejiang University School of Medicine (No.2015-023). Written informed consent was obtained from all individuals included in this study. The research related to animal use has been complied with the guidelines of Institutional Animal Care and Use Committee (IACUC). The maximum tumor size must not exceed $20 \mathrm{~mm}(2.0 \mathrm{~cm})$ and this size was not exceeded at any point during the duration of our study. The Ethics Committee of the Second Affiliated Hospital of Zhejiang University School of Medicine approved the animal experiments.

\section{Consent for publication}

Not Applicable.

\section{Competing interests}

The authors declare that they have no competing interests.

\section{Author details}

'Department of Gastroenterology, The Second Affiliated Hospital, School of Medicine, Zhejiang University, Hangzhou 310009, Zhejiang, Province, China. ${ }^{2}$ Emergency Department, The Second Affiliated Hospital, School of Medicine, Zhejiang University, Hangzhou, Zhejiang Province, China.

Received: 9 October 2020 Accepted: 26 August 2021

Published online: 03 September 2021

\section{References}

1. Siegel RL, Miller KD, Jemal A. Cancer statistics, 2019. CA Cancer J Clin. 2019; 69(1):7-34. https://doi.org/10.3322/caac.21551.

2. Bray F, Ferlay J, Soerjomataram I, Siegel RL, Torre LA, Jemal A. Global cancer statistics 2018: GLOBOCAN estimates of incidence and mortality worldwide for 36 cancers in 185 countries. CA Cancer J Clin. 2018:68(6):394-424. https://doi.org/10.3322/caac.21492.

3. Feng RM, Zong YN, Cao SM, Xu RH. Current cancer situation in China: good or bad news from the 2018 global cancer statistics? Cancer Commun (Lond). 2019;39(1):22. https://doi.org/10.1186/s40880-019-0368-6.

4. Gebert LFR, MacRae IJ. Regulation of microRNA function in animals. Nat Rev Mol Cell Biol. 2019;20(1):21-37. https://doi.org/10.1038/s41580-018-0045-7.

5. Iftikhar H, Carney GE. Evidence and potential in vivo functions for biofluid miRNAs: from expression profiling to functional testing: potential roles of extracellular miRNAs as indicators of physiological change and as agents of intercellular information exchange. Bioessays. 2016;38(4):367-78. https://doi. org/10.1002/bies.201500130

6. Jafarzadeh-Esfehani R, Mostafa Parizadeh S, Sabeti Aghabozorgi A, Yavari N, Sadr-Nabavi A, Alireza Parizadeh S, et al. Circulating and tissue microRNAs as a potential diagnostic biomarker in patients with thrombotic events. J Cell Physiol. 2020;235(10):6393-403. https://doi.org/10.1002/jcp.29639.

7. Kloten V, Neumann MHD, Di Pasquale F, Sprenger-Haussels M, Shaffer JM, Schlumpberger $\mathrm{M}$, et al. Multicenter evaluation of circulating plasma MicroRNA extraction technologies for the development of clinically feasible reverse transcription quantitative PCR and next-generation sequencing analytical work flows. Clin Chem. 2019;65(9):1132-40. https://doi.org/10.13 73/clinchem.2019.303271.

8. Mitchell PS, Parkin RK, Kroh EM, Fritz BR, Wyman SK, Pogosova-Agadjanyan EL, et al. Circulating microRNAs as stable blood-based markers for cancer detection. Proc Natl Acad Sci U S A. 2008;105(30):10513-8. https://doi.org/1 0.1073/pnas.0804549105.

9. Vigneron N, Vernon M, Meryet-Figuiere M, Lambert B, Briand M, Louis MH, et al. Predictive relevance of circulating miR-622 in patients with newly diagnosed and recurrent high-grade serous ovarian carcinoma. Clin Chem. 2020;66(2):352-62. https://doi.org/10.1093/clinchem/hvz013.

10. Wu J, Ji X, Zhu L, Jiang Q, Wen Z, Xu S, et al. Up-regulation of microRNA1290 impairs cytokinesis and affects the reprogramming of colon cancer cells. Cancer Lett. 2013;329(2):155-63. https://doi.org/10.1016/j.canlet.2012.1 0.038 .

11. Ma Q, Wang Y, Zhang H, Wang F. miR-1290 contributes to colorectal cancer cell proliferation by targeting INPP4B. Oncol Res. 2018;26(8):1167-74. https:// doi.org/10.3727/096504017X15051741798389.

12. Mao Y, Liu J, Zhang D, Li B. MiR-1290 promotes cancer progression by targeting nuclear factor I/X (NFIX) in esophageal squamous cell carcinoma (ESCC). Biomed Pharmacother. 2015;76:82-93.

13. Lin M, Shi C, Lin X, Pan J, Shen S, Xu Z, et al. sMicroRNA-1290 inhibits cells proliferation and migration by targeting FOXA1 in gastric cancer cells. Gene. 2016;582(2):137-42. https://doi.org/10.1016/j.gene.2016.02.001.

14. Huang J, Shen M, Yan M, Cui Y, Gao Z, Meng X. Exosome-mediated transfer of miR-1290 promotes cell proliferation and invasion in gastric cancer via NKD1. Acta Biochim Biophys Sin Shanghai. 2019;51(9):900-7. https://doi. org/10.1093/abbs/gmz077.

15. Li A, Yu J, Kim H, Wolfgang CL, Canto Ml, Hruban RH, et al. MicroRNA array analysis finds elevated serum miR-1290 accurately distinguishes patients with low-stage pancreatic cancer from healthy and disease controls. Clin Cancer Res. 2013;19(13):3600-10. https://doi.org/10.1158/1078-0432. CCR-12-3092

16. Wei J, Yang L, Wu Y-N, Xu J. Serum miR-1290 and miR-1246 as potential diagnostic biomarkers of human pancreatic cancer. J Cancer. 2020;11(6): 1325-33. https://doi.org/10.7150/jca.38048.

17. Moltzahn F, Olshen AB, Baehner L, Peek A, Fong L, Stoppler $H$, et al. Microfluidic-based multiplex qRT-PCR identifies diagnostic and prognostic 
microRNA signatures in the sera of prostate cancer patients. Cancer Res. 2011;71(2):550-60. https://doi.org/10.1158/0008-5472.CAN-10-1229.

18. Tzimagiorgis G, Michailidou EZ, Kritis A, Markopoulos AK, Kouidou S. Recovering circulating extracellular or cell-free RNA from bodily fluids. Cancer Epidemiol. 2011;35(6):580-9. https://doi.org/10.1016/j.canep.2011.02. 016.

19. Danese E, Minicozzi AM, Benati M, Paviati E, Lima-Oliveira G, Gusella M, et al. Reference miRNAs for colorectal cancer: analysis and verification of current data. Sci Rep. 2017;7(1):8413. https://doi.org/10.1038/s41598-017-08784-3.

20. Dunaeva M, Blom J, Thurlings R, Pruijn GJM. Circulating serum miR-223-3p and miR-16-5p as possible biomarkers of early rheumatoid arthritis. Clin Exp Immunol. 2018;193(3):376-85. https://doi.org/10.1111/cei.13156.

21. Zhou J, Li X, Wu X, Zhang T, Zhu Q, Wang X, et al. Exosomes released from tumor-associated macrophages transfer miRNAs that induce a Treg/Th17 cell imbalance in epithelial ovarian cancer. Cancer Immunol Res. 2018;6(12): 1578-92. https://doi.org/10.1158/2326-6066.CIR-17-0479.

22. Shen Y, Ding Y, Ma Q, Zhao L, Guo X, Shao Y, et al. Identification of novel circulating miRNA biomarkers for the diagnosis of esophageal squamous cell carcinoma and squamous dysplasia. Cancer Epidemiol Biomark Prev. 2019;28(7):1212-20. https://doi.org/10.1158/1055-9965.EPI-18-1199.

23. Blondal T, Jensby Nielsen S, Baker A, Andreasen D, Mouritzen P, Wrang Teilum M, et al. Assessing sample and miRNA profile quality in serum and plasma or other biofluids. Methods. 2013;59(1):S1-6. https://doi.org/10.1016/ j.ymeth.2012.09.015.

24. McDonald JS, Milosevic D, Reddi HV, Grebe SK, Algeciras-Schimnich A. Analysis of circulating microRNA: preanalytical and analytical challenges. Clin Chem. 2011;57(6):833-40. https://doi.org/10.1373/dlinchem.2010.157198.

25. Kim DJ, Linnstaedt S, Palma J, Park JC, Ntrivalas E, Kwak-Kim JY, et al. Plasma components affect accuracy of circulating cancer-related microRNA quantitation. J Mol Diagn. 2012;14(1):71-80. https://doi.org/10.1016/j. jmoldx.2011.09.002.

26. Foye C, Yan IK, David W, Shukla N, Habboush Y, Chase L, et al. Comparison of miRNA quantitation by Nanostring in serum and plasma samples. PLoS One. 2017;12(12):e0189165. https://doi.org/10.1371/journal.pone.0189165.

27. Tavano F, Gioffreda D, Valvano MR, Palmieri O, Tardio M, Latiano TP, et al. Droplet digital PCR quantification of miR-1290 as a circulating biomarker for pancreatic cancer. Sci Rep. 2018;8(1):16389. https://doi.org/10.1038/s41598018-34597-z.

28. Imaoka H, Toiyama Y, Fujikawa H, Hiro J, Saigusa S, Tanaka K, et al. Circulating microRNA-1290 as a novel diagnostic and prognostic biomarker in human colorectal cancer. Ann Oncol. 2016;27(10):1879-86. https://doi. org/10.1093/annonc/mdw279.

29. Liu X, Xu X, Pan B, He B, Chen X, Zeng K, et al. Circulating miR-1290 and miR-320d as novel diagnostic biomarkers of human colorectal cancer. J Cancer. 2019;10(1):43-50. https://doi.org/10.7150/jca.26723.

30. Sun H, Wang L, Zhao Q, Dai J. Diagnostic and prognostic value of serum miRNA-1290 in human esophageal squamous cell carcinoma. Cancer Biomarkers : Section A Dis Markers. 2019;25(4):381-7. https://doi.org/1 $0.3233 / C B M-190007$

31. Khalighfard S, Kalhori MR, Haddad P, Khori V, Alizadeh AM. Enhancement of resistance to chemo-radiation by hsa-miR-1290 expression in glioblastoma cells. Eur J Pharmacol. 2020;880:173144.

32. Ye L, Jiang T, Shao H, Zhong L, Wang Z, Liu Y, et al. miR-1290 is a biomarker in DNA-mismatch-repair-deficient colon cancer and promotes resistance to 5-fluorouracil by directly targeting hMSH2. Mol Ther Nucleic Acids. 2017;7: 453-64. https://doi.org/10.1016/j.omtn.2017.05.006.

33. Nakashima H, Yoshida R, Hirosue A, Kawahara K, Sakata J, Arita H, et al. Circulating miRNA-1290 as a potential biomarker for response to chemoradiotherapy and prognosis of patients with advanced oral squamous cell carcinoma: a single-center retrospective study. Tumour Biol. 2019;41(3):1010428319826853. https://doi.org/10.1177/1010428319826853.

34. Hardy SD, Shinde A, Wang WH, Wendt MK, Geahlen RL. Regulation of epithelial-mesenchymal transition and metastasis by TGF- $\beta$, P-bodies, and autophagy. Oncotarget. 2017;8(61):103302-14. https://doi.org/10.18632/ oncotarget.21871.

35. Shinde A, Libring S, Alpsoy A, Abdullah A, Schaber JA, Solorio L, et al. Autocrine fibronectin inhibits breast cancer metastasis. Mol Cancer Res. 2018;16(10):1579-89. https://doi.org/10.1158/1541-7786.MCR-18-0151.

36. Shinde A, Wilmanski T, Chen H, Teegarden D, Wendt MK. Pyruvate carboxylase supports the pulmonary tropism of metastatic breast cancer. Breast Cancer Res. 2018;20(1):76. https://doi.org/10.1186/s13058-018-1008-9.
37. Shinde A, Hardy SD, Kim D, Akhand SS, Jolly MK, Wang WH, et al. Spleen tyrosine kinase-mediated autophagy is required for epithelial-mesenchymal plasticity and metastasis in breast cancer. Cancer Res. 2019;79(8):1831-43. https://doi.org/10.1158/0008-5472.CAN-18-2636.

38. Libring S, Shinde A, Chanda MK, Nuru M, George H, Saleh AM, Abdullah A, Kinzer-Ursem TL, Calve S, Wendt MK, et al. The Dynamic Relationship of Breast Cancer Cells and Fibroblasts in Fibronectin Accumulation at Primary and Metastatic Tumor Sites. Cancers. 2020;12(5):1270.

39. Shinde A, Paez JS, Libring S, Hopkins K, Solorio L, Wendt MK. Transglutaminase-2 facilitates extracellular vesicle-mediated establishment of the metastatic niche. Oncogenesis. 2020;9(2):16. https://doi.org/10.1038/ s41389-020-0204-5.

\section{Publisher's Note}

Springer Nature remains neutral with regard to jurisdictional claims in published maps and institutional affiliations.
Ready to submit your research? Choose BMC and benefit from:

- fast, convenient online submission

- thorough peer review by experienced researchers in your field

- rapid publication on acceptance

- support for research data, including large and complex data types

- gold Open Access which fosters wider collaboration and increased citations

- maximum visibility for your research: over $100 \mathrm{M}$ website views per year

At BMC, research is always in progress.

Learn more biomedcentral.com/submissions 